\title{
Eating habits of a population undergoing a rapid dietary transition: portion sizes of traditional and non-traditional foods and beverages consumed by Inuit adults in Nunavut, Canada
}

\author{
Tony Sheehy ${ }^{1}$, Cindy Roache ${ }^{2}$ and Sangita Sharma ${ }^{2 *}$
}

\begin{abstract}
Background: To determine the portion sizes of traditional and non-traditional foods being consumed by Inuit adults in three remote communities in Nunavut, Canada.

Methods: A cross-sectional study was carried out between June and October, 2008. Trained field workers collected dietary data using a culturally appropriate, validated quantitative food frequency questionnaire (QFFQ) developed specifically for the study population.

Results: Caribou, muktuk (whale blubber and skin) and Arctic char (salmon family), were the most commonly consumed traditional foods; mean portion sizes for traditional foods ranged from $10 \mathrm{~g}$ for fermented seal fat to $424 \mathrm{~g}$ for fried caribou. Fried bannock and white bread were consumed by $>85 \%$ of participants; mean portion sizes for these foods were $189 \mathrm{~g}$ and $70 \mathrm{~g}$, respectively. Sugar-sweetened beverages and energy-dense, nutrientpoor foods were also widely consumed. Mean portion sizes for regular pop and sweetened juices with added sugar were $663 \mathrm{~g}$ and $572 \mathrm{~g}$, respectively. Mean portion sizes for potato chips, pilot biscuits, cakes, chocolate and cookies were $59 \mathrm{~g}, 59 \mathrm{~g}, 106 \mathrm{~g}, 59 \mathrm{~g}$, and $46 \mathrm{~g}$, respectively.

Conclusions: The present study provides further evidence of the nutrition transition that is occurring among Inuit in the Canadian Arctic. It also highlights a number of foods and beverages that could be targeted in future nutritional intervention programs aimed at obesity and diet-related chronic disease prevention in these and other Inuit communities.
\end{abstract}

Keywords: Food portion sizes, Nutrition transition, Inuit, Nunavut, Canadian arctic

\section{Introduction}

The traditional diet upon which Inuit of Arctic Canada, Alaska, Greenland and Chukotka (Russia) survived for millennia was based on a wide range of nutrient-dense foods obtained from the local environment, including wild game, marine mammals, fish, birds, and seasonal roots, stems, tubers, wild berries and edible seaweed [1-9]. Within the last fifty years, Inuit have come under increasing pressure to leave behind their traditional way of life and acculturate to the values of Western society

\footnotetext{
* Correspondence: gita.sharma@ualberta.ca

${ }^{2}$ Department of Medicine, University of Alberta, \#5-10 University Terrace, 8303 - 112 Street, Edmonton AB T6G 2T4, Canada

Full list of author information is available at the end of the article
}

$[3,7,10]$. This change in lifestyle has brought about a dramatic nutrition transition characterized by a decrease in the consumption of traditional foods and an increasing reliance on processed, store-bought foods imported from the south [7,11-20]. There is significant and valid concern for the health implications of consuming increased amounts of these fat- and sugar-rich foods $[8,14]$.

Nunavut is the easternmost of three territories in Arctic Canada and consists of twenty-five remote and isolated communities spread across nearly two million square kilometers [21]. The population of Nunavut is approximately 33,000 [22] with some $85 \%$ of inhabitants being Inuit [21]. Despite having the youngest population in Canada [23], Nunavut is experiencing increasing rates 
of obesity and chronic non-communicable diseases. Obesity rates in Nunavut have increased from 23\% in 1992 to $37 \%$ in 2004 [24]. Inuit have disproportionately higher rates of cancer compared with southern Canadians, including the highest incidence of salivary gland and lung cancers in the world and one of the highest rates of nasopharangeal cancer [25]. Age-standardized rates of cancer mortality (per 100,000 people) in 2007 were 340 in Nunavut compared with 166 for the general Canadian population [26]. Age-standardized mortality rates for diseases of the circulatory system (per 100,000 people) in 2000-2004 were 249 in Nunavut compared with 192 for the general Canadian population [27]. Life expectancy in Inuit-inhabited areas trails the Canadian average by more than twelve years [28]. Due to these high chronic disease prevalence rates and the remoteness of the communities in the territory, Nunavut's health care system is under constant pressure due to the high cost of health service delivery [8]. Thus, from a health systems perspective, investing in chronic disease prevention is essential if the territory is to adequately and sustainably manage health care costs in the long term as its young population ages.

Obesity is a key target for nutritional interventions aimed at chronic disease prevention due to the fact that excess body weight is linked to a number of deleterious health effects including increased risk of coronary heart disease, ischemic stroke, hypertension, dyslipidemia, type 2 diabetes mellitus, joint disease, cancer, asthma, and a host of other chronic conditions [29]. Research suggests that over $86 \%$ of the variance in food intake among humans is due to factors in their immediate environment [30]. One important environmental factor that is believed to be contributing to the obesity epidemic is food portion size [31-40]. Portion sizes of virtually all foods and beverages prepared for immediate consumption have increased over the last few decades [31,32,41-43]. Increasing the amount of food [44-46] or caloric beverages [47] served on a given eating occasion results in an increase in energy intake, while serving larger food portion sizes for several days leads to a sustained increase in energy intake without any evidence of compensatory behaviour [48-50]. Nutritional interventions that focus on reducing portion sizes of energy-dense foods and increasing portion sizes of low-energy-dense foods such as soups, fruits and vegetables may represent one possible approach to moderating energy intake [36,51-53]. However, before such interventions can be attempted among Inuit, up-to-date information on the typical portion sizes of foods that are habitually consumed by this population is required. Previously, a culturally appropriate, validated quantitative food frequency questionnaire (QFFQ) was developed specifically for Inuit in Nunavut [54]. The objective of this study was to use this instrument to determine the portion sizes of traditional and non-traditional foods that are currently being consumed by Inuit adults in three remote communities undergoing a nutrition transition in Nunavut, Canada.

\section{Methods}

The setting, recruitment methods and data collection procedures have been described in detail elsewhere [8]. In brief, a cross-sectional study was carried out in three communities in Nunavut, Canada, between June and October, 2008. Communities A, B and C were chosen to represent Inuit communities with varying population sizes, socioeconomic status and degrees of acculturation. Study participants were randomly selected using up-todate community housing maps to ensure that those who had different proximities to stores and land for hunting were included. Residents aged $<19$ years and pregnant/ lactating women were excluded due to their different nutritional requirements. The person in the household who was primarily responsible for shopping for and preparing foods was selected for interview to capture the kinds of foods commonly eaten within the population. Written informed consent was obtained from all participants.

Trained field workers collected dietary data using a culturally appropriate, validated QFFQ developed specifically for the study population $[54,55]$. Data on demographics, socioeconomic status, and heights and weights of participants for the calculation of BMI were also collected. The QFFQ contained 150 food items (65 meat, fish and poultry; 19 vegetables; 14 desserts and snacks; 13 fruits; 12 breads and cereals; 12 dairy; nine beverages; three alcoholic drinks; two sugar and sweetener products; one creamer product), of which 39 were traditional foods [8]. Participants were asked to report the frequency of consumption over a 30-day period by choosing from eight categories, which ranged from 'never' to 'two or more times per day.' For each food item, a separate question asked subjects to estimate how much they usually eat at one time. Three-dimensional food models (NASCO Company, 901 Jamesville Ave, Fort Atkinson, Wisconsin 53538) and household units (e.g., bowls, mugs, and spoons) were carefully chosen with input from local Inuit to best estimate the amount of foods and beverages consumed. Portion size was defined as the sizes in which foods are served at home and the units in which they are consumed in one sitting [56]. Data were examined by the project coordinator and if any set of data was incomplete the interviewer recontacted the respondent to obtain the missing information. Upon completion of interviews, participants were given a CAD $\$ 25$ gift certificate for a local store to 
recognize their contribution and thank them for their time.

For each of the foods and beverages listed on the QFFQ, the mean, standard deviation and median portion size in grams (for consumers only) were determined using SAS statistical software, version 9.2 (SAS Version 9.2, SAS Institute Inc., Cary, NC).

Institutional Review Board approval was obtained from the Committee on Human Studies at the University of Hawaii and the Office of Human Research Ethics at the University of North Carolina at Chapel Hill. The Nunavut Research Institute licensed the study.

\section{Results}

In total, 211 Inuit adults (175 women and 36 men) participated in the study. Participants ranged in age from 19-89 years, with a mean (SD) age of 42.1 (15.0) years for men and 42.2 (13.2) years for women. The response rate was $69-93 \%$, varying by community. There were 71 participants from Community A, 74 participants from Community B and 66 participants from Community C. Mean (SD) BMIs for participants from communities A, $B$ and $C$ were $29.4(7.4) \mathrm{kg} / \mathrm{m}^{2}, 29.4(8.1) \mathrm{kg} / \mathrm{m}^{2}$ and 30.4 (7.7) $\mathrm{kg} / \mathrm{m}^{2}$, respectively. At least two-thirds of participants in each community were either overweight or obese (BMI $\geq 25.0 \mathrm{~kg} / \mathrm{m}^{2}$ ) according to WHO cut-off points [57].

The mean (SD) and median portion sizes (g) of traditional meats, traditional fish, and soups/stews consumed by Inuit adults in these three remote communities are shown in Table 1. Caribou was the most popular traditional meat, followed by muktuk (whale blubber and skin) and seal. Less than $20 \%$ of participants consumed other traditional meats such as goose, muskox, polar bear or ptarmigan and less than a third of participants consumed bone marrow or organ meats (e.g. heart, kidney, stomach, intestine). Mean portion sizes for individual items in this category ranged from $10 \mathrm{~g}$ for fermented seal fat (liquid) to $424 \mathrm{~g}$ for stir-fried caribou. Mean portion sizes for raw caribou and raw seal were $274 \mathrm{~g}$ and $195 \mathrm{~g}$, respectively. With regard to fish, more than half of the participants consumed Arctic char; other traditional fish such as trout or white fish were consumed by fewer participants. Mean portion sizes for fish items ranged from $83 \mathrm{~g}$ for battered and/or fried fish to $370 \mathrm{~g}$ for raw Arctic char. Soups or stews were consumed by the majority of participants. Caribou soup or stew was consumed by three-quarters of participants with an average portion size of $475 \mathrm{~g}$. Fish soup or chowder was consumed by one-third of participants, with an average portion size of $466 \mathrm{~g}$.

The mean (SD) and median portion sizes (g) of fruits and vegetables consumed by this Inuit population are shown in Table 2. About three-quarters of participants consumed apples, bananas, grapes or oranges and approximately $60 \%$ consumed canned fruit or fruit cocktail. However, most other fruits on the QFFQ were consumed by less than one-third of participants. The mean portion sizes for fruits ranged from $36 \mathrm{~g}$ for grapes to $260 \mathrm{~g}$ for fresh fruit salad. With regard to vegetables, slightly more than half the participants consumed carrots, corn, or frozen vegetables, but consumption of other vegetables was limited, both in terms of variety and amount. Mean portion sizes for vegetables ranged from $78 \mathrm{~g}$ for corn to $177 \mathrm{~g}$ for salad.

The mean (SD) and median portion sizes (g) of cerealbased foods (including breads, pancakes, breakfast cereals, porridges, noodles, macaroni and rice) and potatoes consumed by Inuit adults in this study are shown in Table 3. More than $85 \%$ of participants consumed fried bannock, whereas baked bannock was consumed by only $19.4 \%$ of participants. Mean portion size of fried bannock was higher than that of baked bannock (189 g vs $166 \mathrm{~g}$, respectively). White bread was consumed by $87.7 \%$ of participants, whereas only $57.8 \%$ of participants consumed whole wheat bread. Mean portion sizes for white and whole wheat bread were more or less the same (approximately 70-74 g). Breakfast cereals were consumed by slightly less than half of the participants. Mean portion sizes for sweet cereals were higher than those for low-sugar cereals (46 g vs $29 \mathrm{~g}$, respectively). Noodles, macaroni, potatoes, potato products and especially rice were consumed by a large percentage of participants. Mean portion sizes for these food items ranged from $97 \mathrm{~g}$ for hash browns/potato patties/French fries to $475 \mathrm{~g}$ for noodles.

The mean (SD) and median portion sizes (g) of dairy products, eggs, and non-traditional meats and meat products consumed by Inuit adults in this study is shown in Table 4 . Milk ( $2 \%$ fat) was consumed by more than half the participants, although other milks (i.e. skim, $1 \%$ fat, or whole milk) were consumed by less than one-tenth of participants. About one-fifth of participants consumed milkshake, hot chocolate or canned/evaporated milk products. Portion sizes for milks were broadly similar at approximately $343-380$ g. Hard cheese and eggs (chicken or duck) were consumed by three-quarters of participants. The most popular non-traditional meat products were hot dogs/wieners/sausages, which were consumed by $75.8 \%$ of participants with a mean portion size of $115 \mathrm{~g}$. At least half of participants reported consuming beef hamburgers, beef steak, pork chops, pork or beef ribs, chicken legs and chicken wings, while other processed meat products including salami/bologna, pepperoni, jerky and canned meats were also widely consumed.

The mean (SD) and median portion sizes (g) of energy-dense, nutrient-poor foods (e.g. chips, popcorn, 
Table 1 Mean (SD) and median portion sizes (g) of traditional meats, poultry, fish and soups/stews consumed by Inuit adults in three remote communities in Nunavut, Canada

\begin{tabular}{|c|c|c|c|c|}
\hline \multirow[t]{2}{*}{ Food item } & \multirow{2}{*}{$\begin{array}{l}\text { Consumers } \\
(\%)\end{array}$} & \multicolumn{3}{|c|}{ Portion size $(g)$} \\
\hline & & Mean & SD & Median \\
\hline \multicolumn{5}{|l|}{ Traditional meats/poultry } \\
\hline Bone marrow, any & 31.3 & 34 & 22 & 32 \\
\hline Caribou, aged & 2.4 & 251 & 138 & 279 \\
\hline Caribou fat, hard & 38.4 & 62 & 52 & 32 \\
\hline Caribou, boiled, baked or roast & 82 & 191 & 107 & 149 \\
\hline Caribou, dried & 60.2 & 201 & 166 & 153 \\
\hline Caribou, fried, not incl. stir fry & 55.9 & 96 & 59 & 58 \\
\hline Caribou, raw & 66.4 & 274 & 205 & 186 \\
\hline Caribou, stir fried & 34.1 & 424 & 190 & 428 \\
\hline Goose, baked, boiled or roasted & 19.4 & 88 & 75 & 82 \\
\hline Heart or kidney, any & 24.6 & 389 & 267 & 200 \\
\hline Liver, any, not incl. seal & 12.3 & 124 & 74 & 110 \\
\hline Muktuk & 48.3 & 217 & 178 & 194 \\
\hline Muskox, boiled & 10 & 161 & 106 & 173 \\
\hline Muskox, fried & 5.7 & 143 & 73 & 143 \\
\hline Muskox, fat & 3.3 & 39 & 30 & 32 \\
\hline Polar bear, boiled & 6.2 & 169 & 136 & 149 \\
\hline Ptarmigan & 4.3 & 277 & 261 & 119 \\
\hline Seal, cooked & 37.9 & 184 & 96 & 159 \\
\hline Seal fat, fermented or fresh, hard & 12.3 & 36 & 28 & 26 \\
\hline Seal fat, fermented, liquid & 4.3 & 10 & 4 & 10 \\
\hline Seal liver & 24.6 & 145 & 132 & 88 \\
\hline Seal, raw, not incl. liver & 12.3 & 195 & 143 & 167 \\
\hline Stomach or intestine, any & 12.3 & 133 & 109 & 101 \\
\hline \multicolumn{5}{|l|}{ Traditional fish } \\
\hline Char, smoked & 14.7 & 95 & 66 & 62 \\
\hline Char, boiled & 53.1 & 256 & 112 & 209 \\
\hline Char, dried & 60.7 & 86 & 49 & 93 \\
\hline Char, raw & 63 & 370 & 198 & 261 \\
\hline Fish head, large & 9 & 269 & 102 & 227 \\
\hline Fish head, medium & 21.8 & 151 & 73 & 142 \\
\hline Fish head, small & 7.6 & 92 & 26 & 89 \\
\hline Fish, baked & 28 & 204 & 143 & 185 \\
\hline Fish, battered and/or fried & 42.7 & 83 & 43 & 84 \\
\hline Trout, baked or broiled & 15.2 & 219 & 94 & 201 \\
\hline Trout, dried & 21.8 & 179 & 127 & 165 \\
\hline Trout, raw & 13.7 & 227 & 110 & 237 \\
\hline White fish, dried & 7.1 & 105 & 71 & 110 \\
\hline White fish, raw & 7.1 & 261 & 105 & 237 \\
\hline \multicolumn{5}{|l|}{ Soups/stews } \\
\hline Beef stew, homemade or canned & 41.7 & 360 & 146 & 368 \\
\hline Caribou soup or stew & 75.8 & 475 & 199 & 405 \\
\hline
\end{tabular}


Table 1 Mean (SD) and median portion sizes (g) of traditional meats, poultry, fish and soups/stews consumed by Inuit adults in three remote communities in Nunavut, Canada (Continued)

\begin{tabular}{|c|c|c|c|c|}
\hline Char or clam chowder or any fish soup & 34.6 & 466 & 171 & 452 \\
\hline Mushroom or vegetable soup & 49.3 & 349 & 121 & 381 \\
\hline Soup, any, with beef, ham, chicken, duck, goose & 53.6 & 419 & 160 & 418 \\
\hline
\end{tabular}

desserts, candies/candy bars, cookies and crackers) and beverages consumed by this population of Inuit adults are shown in Table 5. More than three-quarters of participants reported consuming potato chips and pilot biscuits, while at least half the participants consumed cakes/muffins, chocolate, cookies and crackers. Mean portion sizes for foods in this category ranged from $13 \mathrm{~g}$ for popcorn to $170 \mathrm{~g}$ for cheesecake. More than threequarters of participants reported consuming tea, coffee and regular non-alcoholic beverages (regular pop and sweetened juices with added sugar), whereas less than $20 \%$ consumed diet or sugar-free beverages. Regular pop was consumed in larger portion sizes than diet pop (663 g vs $459 \mathrm{~g}$, respectively), and sweetened juices with added sugar were consumed in larger portions than sugar-free juices (572 g vs $514 \mathrm{~g}$, respectively). Alcoholic beverages were consumed by less than one-third of participants.

\section{Discussion}

The present study provides up-to-date information on portion sizes of traditional and non-traditional foods and beverages as consumed by Inuit adults in three remote communities in Nunavut in the Canadian Arctic. Caribou, muktuk and Arctic char were the most widely consumed traditional foods. However, sugar-sweetened beverages and energy-dense, nutrient-poor foods (e.g. potato chips, pilot biscuits, cakes, chocolate, cookies and crackers) were widely consumed also. A number of factors may have contributed to the decline in traditional

Table 2 Mean (SD) and median portion sizes (g) of fruits and vegetables consumed by Inuit adults in three remote communities in Nunavut, Canada

\begin{tabular}{|c|c|c|c|c|}
\hline \multirow[t]{2}{*}{ Food item } & \multirow{2}{*}{$\begin{array}{l}\text { Consumers } \\
\text { (\%) }\end{array}$} & \multicolumn{3}{|c|}{ Portion size $(g)$} \\
\hline & & Mean & SD & Median \\
\hline \multicolumn{5}{|l|}{ Fruit } \\
\hline Apple & 73.9 & 145 & 56 & 138 \\
\hline Banana & 84.4 & 156 & 68 & 136 \\
\hline Blueberries, raspberries, blackberries, any other & 41.7 & 99 & 43 & 104 \\
\hline Dried fruits incl. raisins & 42.2 & 108 & 74 & 87 \\
\hline Fruit or fruit cocktail, any, canned in syrup & 59.7 & 194 & 78 & 188 \\
\hline Fruit salad, fresh & 14.7 & 260 & 136 & 183 \\
\hline Fruit, frozen, incl. peaches, strawberries, blueberries & 29.9 & 186 & 71 & 164 \\
\hline Grapes & 74.4 & 36 & 25 & 24 \\
\hline Kiwi & 25.6 & 125 & 72 & 91 \\
\hline Mango & 6.6 & 152 & 59 & 155 \\
\hline Orange & 74.4 & 146 & 64 & 131 \\
\hline Peaches and nectarines & 13.7 & 133 & 52 & 117 \\
\hline Strawberries & 29.9 & 115 & 52 & 108 \\
\hline \multicolumn{5}{|l|}{ Vegetables } \\
\hline Carrot, eaten alone & 54.5 & 159 & 229 & 114 \\
\hline Corn & 55.5 & 78 & 28 & 73 \\
\hline Corn on the cob & 28.4 & 159 & 72 & 146 \\
\hline Fresh vegetables, other & 29.4 & 97 & 41 & 118 \\
\hline Frozen vegetables, any, incl. mixed & 58.3 & 92 & 36 & 117 \\
\hline Salad in a bowl & 37.9 & 177 & 59 & 207 \\
\hline Tomatoes, canned & 14.2 & 167 & 76 & 183 \\
\hline Vegetables, canned, any & 17.5 & 97 & 50 & 73 \\
\hline
\end{tabular}




\begin{tabular}{|c|c|c|c|c|}
\hline \multirow[t]{2}{*}{ Food item } & \multirow{2}{*}{$\begin{array}{l}\text { Consumers } \\
\text { (\%) }\end{array}$} & \multicolumn{3}{|c|}{ Portion size $(g)$} \\
\hline & & Mean & SD & Median \\
\hline \multicolumn{5}{|l|}{ Breads/pancakes } \\
\hline Bannock, baked & 19.4 & 166 & 127 & 139 \\
\hline Bannock, fried & 85.8 & 189 & 116 & 149 \\
\hline Pancakes or waffles, incl. Eggo waffles & 51.7 & 88 & 32 & 91 \\
\hline White bread, incl. toast, sandwiches, rolls and bagels & 87.7 & 70 & 30 & 60 \\
\hline Whole wheat bread & 57.8 & 74 & 25 & 67 \\
\hline \multicolumn{5}{|l|}{ Cereals/porridges } \\
\hline Low sugar cereals (e.g. Corn Flakes, Rice Krispies, Cheerios) & 49.3 & 29 & 10 & 28 \\
\hline Porridge, home-made & 25.6 & 186 & 91 & 142 \\
\hline Quaker Oats or porridge in a package & 42.7 & 254 & 103 & 189 \\
\hline Sweet cereals, incl. Frosted Flakes or Honey Nut Cheerios & 43.1 & 46 & 17 & 51 \\
\hline \multicolumn{5}{|l|}{ Noodles/macaroni/rice } \\
\hline Macaroni and cheese or Kraft Dinner & 67.3 & 300 & 111 & 343 \\
\hline Noodles & 61.1 & 475 & 212 & 450 \\
\hline Rice, any & 85.3 & 148 & 76 & 131 \\
\hline \multicolumn{5}{|l|}{ Potatoes } \\
\hline Hash browns or potato patties or French fries & 67.8 & 97 & 61 & 77 \\
\hline Potato salad & 19.4 & 158 & 84 & 175 \\
\hline Potato, baked or boiled & 60.7 & 141 & 60 & 119 \\
\hline Potato, mashed, incl. instant & 66.8 & 125 & 54 & 103 \\
\hline
\end{tabular}

food consumption that has been reported among Arctic indigenous peoples in recent years; these include lack of time for hunting due to increased involvement in the wage economy, high cost of hunting equipment, ammunition and fuel, a decline in communal food sharing networks, concerns about food supply contamination by organochlorines and heavy metals, and reduced animal populations and changing migration patterns due to climate change $[7,8,58]$.

The present study also revealed that apart from apple, banana, oranges and grapes, which were consumed by roughly three-quarters of participants, fruit and vegetable consumption by Inuit participants in these 3 communities was generally low. The landscape in this region is tundra and is covered in snow for most of the year; hence there is an almost total reliance on fruits and vegetables that are grown elsewhere and transported to the communities primarily by air freight [7]. Mean daily temperatures are below $0^{\circ} \mathrm{C}$ for approximately nine months of the year and below $-30^{\circ} \mathrm{C}$ for about four months of the year [59]. Transportation and preservation of fresh fruits and vegetables under these conditions is difficult and costly; thus, the produce that is available in the stores is often of poor quality and prohibitively expensive $[7,8]$. Basic nutrition education and healthy dietary skills may also be a barrier to fruit and vegetable consumption in these communities $[7,19]$.

Sweetened beverages were consumed by over threequarters of participants in the present study and the average portion sizes were large. Juices consumed by this population are mainly high sugar beverages such as Kool-Aid $^{\text {TM }}$ (Kraft Foods Inc., Northfield, IL, USA) or Tang $^{\text {Ts }}$ (Kraft Foods Inc., Northfield, IL, USA) [17]. The average portion size for sweetened juices with added sugar was $572 \mathrm{~g}$, which in terms of caloric intake would provide some $879-1130 \mathrm{~kJ}(210-270 \mathrm{kcal})$ [60]. Similarly, the average portion size for regular pop was $663 \mathrm{~g}$ (equivalent to about two standard $330 \mathrm{ml}$ cans), which would provide about 1151-1339 kJ (275-320 kcal) [60]. By comparison, in the United States, the average portion size of sweetened beverages consumed per eating occasion increased from $386 \mathrm{~g}$ to $595 \mathrm{~g}$ between 1977 and 1996 [61]. Energy from caloric beverages is poorly regulated and therefore can add excess calories to daily energy intake $[47,62]$. Sugar-sweetened beverage intake is a significant contributor to weight gain and can lead to increased risk of type 2 diabetes mellitus and cardiovascular disease [63]. Recently, the American Heart Association issued a scientific statement recommending that in order to achieve and maintain healthy weights 
Table 4 Mean (SD) and median portion sizes (g) of dairy products, eggs, and non-traditional meats and meat products consumed by Inuit adults in three remote communities in Nunavut, Canada

\begin{tabular}{|c|c|c|c|c|}
\hline \multirow[t]{2}{*}{ Food item } & \multirow{2}{*}{$\begin{array}{l}\text { Consumers } \\
\text { (\%) }\end{array}$} & \multicolumn{3}{|c|}{ Portion size $(g)$} \\
\hline & & Mean & SD & Median \\
\hline \multicolumn{5}{|l|}{ Milk } \\
\hline Milk, $1 \%$ or skim & 8.1 & 371 & 182 & 259 \\
\hline Milk, $2 \%$ & 57.3 & 343 & 224 & 259 \\
\hline Milk, Carnation, cream, half and half or carnation cream & 21.3 & 68 & 73 & 40 \\
\hline Milk, whole & 3.8 & 354 & 316 & 259 \\
\hline Milkshake or hot chocolate & 22.7 & 380 & 193 & 283 \\
\hline \multicolumn{5}{|l|}{ Cheese } \\
\hline Cream cheese, any & 17.1 & 24 & 32 & 15 \\
\hline Hard cheese incl. Kraft cheese slices & 77.7 & 54 & 36 & 30 \\
\hline \multicolumn{5}{|l|}{ Eggs } \\
\hline Chicken or duck eggs & 75.8 & 93 & 26 & 85 \\
\hline Goose eggs & 14.7 & 218 & 148 & 144 \\
\hline Swan eggs & 2.4 & 202 & 79 & 144 \\
\hline \multicolumn{5}{|l|}{ Beef/pork } \\
\hline Beef hamburgers & 56.9 & 154 & 65 & 101 \\
\hline Beef steak, not incl. stir fry & 51.7 & 158 & 57 & 157 \\
\hline Beef, stir fried & 19.9 & 349 & 129 & 425 \\
\hline Meat pie & 12.8 & 206 & 127 & 170 \\
\hline Pork chops & 59.2 & 116 & 49 & 86 \\
\hline Pork or beef ribs & 53.1 & 120 & 58 & 108 \\
\hline Pork roast & 12.8 & 84 & 50 & 58 \\
\hline Sloppy Joe & 7.1 & 195 & 71 & 146 \\
\hline Spaghetti with ground beef or ground muskox, or beef ravioli & 70.1 & 354 & 122 & 373 \\
\hline \multicolumn{5}{|l|}{ Processed meats } \\
\hline Bacon, fried & 60.2 & 29 & 15 & 24 \\
\hline Beef or muskox jerky & 46.9 & 39 & 21 & 39 \\
\hline Bologna, salami & 52.1 & 52 & 26 & 56 \\
\hline Ham & 30.8 & 92 & 60 & 72 \\
\hline Hot dogs, wieners or sausages & 75.8 & 115 & 51 & 107 \\
\hline Klik or other canned meat & 65.4 & 70 & 57 & 45 \\
\hline Pepperoni sticks & 43.6 & 72 & 40 & 56 \\
\hline \multicolumn{5}{|l|}{ Chicken/turkey } \\
\hline Chicken breast, baked, boiled or roasted & 31.3 & 291 & 158 & 225 \\
\hline Chicken breast, fried, incl. KFC & 14.7 & 140 & 51 & 124 \\
\hline Chicken leg, baked, boiled or roasted & 52.1 & 219 & 116 & 226 \\
\hline Chicken leg, fried, incl. KFC & 22.7 & 216 & 111 & 223 \\
\hline Chicken nuggets or popcorn chicken & 41.2 & 103 & 39 & 96 \\
\hline Chicken wings & 55.5 & 41 & 18 & 36 \\
\hline
\end{tabular}

and decrease cardiovascular risk while at the same time meeting essential nutrient needs, most American women should eat or drink no more than 100 calories per day from added sugars, and most American men should eat or drink no more than 150 calories per day from added sugars [64]. This suggests that Inuit consumers in these communities would need to reduce portion sizes of sugar-sweetened beverages by a very considerable 
Table 5 Mean (SD) and median portion sizes (g) of chips/popcorn, desserts/candies/cookies, crackers and non-alcoholic and alcoholic beverages consumed by Inuit adults in three remote communities in Nunavut, Canada

\begin{tabular}{|c|c|c|c|c|}
\hline \multirow[t]{2}{*}{ Food item } & \multirow{2}{*}{$\begin{array}{l}\text { Consumers } \\
\text { (\%) }\end{array}$} & \multicolumn{3}{|c|}{ Portion size $(g)$} \\
\hline & & Mean & SD & Median \\
\hline \multicolumn{5}{|l|}{ Chips/popcorn } \\
\hline Popcorn & 42.7 & 13 & 6 & 12 \\
\hline Potato chips & 83.4 & 59 & 26 & 60 \\
\hline \multicolumn{5}{|l|}{ Desserts/candies/candy bars/cookies } \\
\hline Cake or muffin, any & 59.7 & 106 & 52 & 117 \\
\hline Cheesecake or similar & 6.6 & 170 & 65 & 134 \\
\hline Chocolate bar, any kind & 60.7 & 59 & 28 & 52 \\
\hline Cookies incl. Oreos, Oatmeal & 50.2 & 38 & 21 & 30 \\
\hline Hard candy, any & 42.2 & 21 & 14 & 18 \\
\hline Pie, blueberry, apple, cherry & 29.4 & 154 & 78 & 118 \\
\hline \multicolumn{5}{|l|}{ Crackers } \\
\hline Crackers incl. Cream Crackers, Premium Plus & 56.9 & 46 & 38 & 31 \\
\hline Crackers incl. Ritz, Wheat Thins or sesame snacks & 29.9 & 20 & 15 & 15 \\
\hline Pilot biscuits, any kind & 75.8 & 59 & 40 & 51 \\
\hline \multicolumn{5}{|l|}{ Regular beverages } \\
\hline Juice sweetened, any kind, with added sugar & 77.7 & 572 & 414 & 527 \\
\hline Pop, regular & 82 & 663 & 706 & 372 \\
\hline \multicolumn{5}{|l|}{ Tea/coffee } \\
\hline Coffee & 81.5 & 1075 & 984 & 752 \\
\hline Tea, any hot tea & 83.9 & 786 & 697 & 502 \\
\hline \multicolumn{5}{|l|}{ Diet/sugar-free beverages } \\
\hline Pop, diet & 17.1 & 459 & 226 & 355 \\
\hline Sugar-free juices & 15.2 & 514 & 403 & 507 \\
\hline \multicolumn{5}{|l|}{ Alcohol } \\
\hline Beer or coolers, any kind & 15.6 & 1826 & 1189 & 1426 \\
\hline Liquor incl. rum, whiskey, vodka or gin & 30.8 & 330 & 418 & 158 \\
\hline Wine, any & 8.1 & 492 & 444 & 374 \\
\hline
\end{tabular}

margin and to replace them with water, tea or coffee (provided that caloric sweeteners and whiteners are used sparingly) or with diet- or sugar-free varieties of the same products.

In the present study, potato chips were consumed by over four-fifths of participants, with an average portion size of $59 \mathrm{~g}$; this would provide roughly 1151-1381 kJ (275-330 kcal), depending on brand [60]. Likewise, chocolate was consumed by almost $60 \%$ of participants, and the energy provided by an average portion (59 g) would be around 1046-1339 kJ (250-320 kcal), depending on brand [60]. Cakes and muffins were consumed by some $60 \%$ of participants and the average portion size was $106 \mathrm{~g}$. In terms of energy content, commercial muffins provide approximately 1159-1360 kJ (277$325 \mathrm{kcal} / 100 \mathrm{~g}$, while commercial cake varieties (e.g. fruit cake, sponge cake, chocolate cake, coffee cake, white cake) provide some 1205-1736 kJ (288-415 kcal)/ $100 \mathrm{~g}$ [60]. Certain other types of refined grain products (e.g. spaghetti, macaroni and noodles) also contributed substantial amounts of energy to consumers in this population due to the large portion sizes consumed. On the other hand, the popularity of soups among participants could be exploited because soups have a high satiety value and elicit strong dietary compensation [65]; eating a low energy-dense soup as a pre-load before a test meal resulted in a $20 \%$ reduction in total energy intake at the meal with no significant effect on hunger or satiety ratings [52]. Thus, the present study has highlighted a number of different types of foods and beverages that could be targeted in future nutritional intervention programs aimed at obesity and diet-related chronic disease prevention in these and other Inuit communities. 
Due to its geographic remoteness, the cost of treating chronic disease in Nunavut is extremely high as a result of the necessity to transport patients to southern cities for medical assessment and treatment [8]. This situation will get markedly worse if, as is predicted, the global obesity epidemic that is currently happening is followed by an epidemic of type 2 diabetes and other cardiovascular disease risk factors [66,67]. Recently, the American Heart Association endorsed the concept of 'primordial prevention' for cardiovascular disease prevention [68]. This approach is based on evidence from the Framingham Heart Study cohort showing that compared with individuals with $\geq 2$ major risk factors, those individuals who had maintained a profile of ideal cardiovascular risk factor levels from young adulthood into middle age had greatly reduced lifetime CVD and non-CVD mortality rates, thereby resulting in an additional 10 years' longevity [69]. Capewell et al. [70] demonstrated that if the majority of the US population reached middle age with this ideal phenotype, more than $90 \%$ of expected coronary heart disease deaths might be prevented. However, it was also argued that to bring about such a change would require an environment that supports health, rather than, as now, promoting obesity, hypertension, diabetes and inactivity [71]. For Nunavut, the implication of these findings is that investment in programs and public health policies that prevent the development of adverse CVD risk factors in its young population could be expected to yield substantial returns in the long term in the form of greatly reduced medical costs and increased longevity and quality of life for its citizens. On the other hand, failure to do so would place its health care system under an increasingly unsustainable burden as its young population ages.

The results of the present study were obtained as part of Healthy Foods North (HFN), a community-based, culturally-appropriate, multi-institutional chronic disease prevention program that has worked at the individual, household, community and institutional level to improve diet and increase physical activity among Inuit in Nunavut $[8,55]$. These data will be useful in developing other nutritional intervention programs designed to reduce dietary risk factors for obesity and chronic diseases in Inuit populations.

A major strength of the present study is the fact that the QFFQ was developed specifically for this Inuit population and thus contains the complete list of foods commonly consumed by them. Also, portion sizes were assessed using three dimensional food models and household units that were chosen with the input of local Inuit residents. The study does, however, have some limitations. Firstly, men were not as well represented as women since the intention was to target the family member who was primarily responsible for purchasing and preparing foods. Therefore, our ability to generalize these results to Inuit men is limited. Secondly, there may have been recall biases among the participants when they reported foods and beverages consumed in the last 30 days. Thirdly, the study only captured summer and autumn consumption and, consequently, did not account for seasonal variability, especially during the winter months. Finally, it should not be assumed that data collected in these three specific communities can be generalized to all Inuit populations.

\section{Conclusions}

This study presented contemporary data on portion sizes of traditional and non-traditional foods and beverages consumed by Inuit in three remote communities in Nunavut, Canada. Caribou, muktuk and Arctic char were the most widely consumed traditional foods. However, energy-dense, nutrient-poor foods and sugarsweetened beverages were widely consumed as well. Based on observed portion sizes and rates of consumption among participants, a number of foods and beverages were highlighted that could be targeted in future nutritional intervention programs aimed at obesity and diet-related chronic disease prevention in these and other Inuit communities. The results of this study may also be useful for nutrition education and for monitoring the ongoing nutrition transition among Inuit in the Canadian Arctic.

\section{Competing interests}

The authors declare that they have no competing interests.

\section{Authors' contributions}

TS participated in manuscript drafting and editing, CR oversaw all field activities and data collection, SS conceptualized and participated in manuscript drafting, design, and critical review. All authors read and approved the final manuscript.

\section{Acknowledgements}

The project was supported by American Diabetes Association Clinical Research award 1-08-CR-57, Government of Nunavut Department of Health and Social Services, and Health Canada.

\section{Author details}

${ }^{1}$ School of Food and Nutritional Sciences, University College Cork, Cork, Republic of Ireland. ${ }^{2}$ Department of Medicine, University of Alberta, \#5-10 University Terrace, 8303 - 112 Street, Edmonton AB T6G 2T4, Canada.

Received: 10 October 2012 Accepted: 22 May 2013

Published: 2 June 2013

\section{References}

1. Draper $\mathrm{HH}$ : The Aboriginal Eskimo diet in modern perspective. Am Anthropol 1977, 79:309-316.

2. Kuhnlein HV, Soueida R, Receveur O: Dietary nutrient profiles of Canadian Baffin Island Inuit differ by food source, season, and age. J Am Diet Assoc 1996, 96:155-162.

3. Shephard RJ, Røde A: The Health Consequences of "Modernization". Cambridge, UK: Cambridge University Press; 1996.

4. Young TK, Reading J, Elias B, O'Neill JD: Type 2 diabetes mellitus in Canada's first nations, status of an epidemic in progress. Can Med Assoc J 2000, 163:561-566. 
5. Kuhnlein HV, Receveur O, Chan HM: Traditional food systems research with Canadian Indigenous Peoples. Int J Circumpolar Health 2001, 60:112-122.

6. Kuhnlein HV, Receveur O: Local cultural animal food contributes high levels of nutrients for Arctic Canadian Indigenous adults and children. J Nutr 2007, 137:1110-1114.

7. Mead E, Gittelsohn J, Kratzmann M, Roache C, Sharma S: Impact of the changing food environment on dietary practices of an Inuit population in Arctic Canada. J Hum Nutr Diet 2010, 23(Suppl. 1):18-26.

8. Sharma S: Assessing diet and lifestyle in the Canadian Arctic Inuit and Inuvialuit to inform a nutrition and physical activity intervention programme. J Hum Nutr Diet 2010, 23(Suppl. 1):5-17.

9. Martin DH: "Now we get lots to eat and they're telling us not to eat it": understanding changes to south-east Labrador Inuit relationships to food. Int. J. Circumpolar Health 2011, 70:384-395.

10. Boult D: The Inuit Way: a Guide to Inuit Culture. Ottawa, Canada: Inuit Women's Association; 1992

11. Receveur O, Boulay M, Kuhnlein HV: Decreasing traditional food use affects diet quality for adult Dene/Métis in 16 communities of the Canadian Northwest Territories. J Nutr 1997, 127:2179-2186.

12. Blanchet $\mathrm{C}$, Dewailly E, Ayotte $\mathrm{P}$, Bruneau S, Receveur O, Holub BJ: Contribution of selected traditional and market foods to the diet of Nunavik Inuit women. Can J Diet Pract Res 2000, 61:50-59.

13. Bjerregaard P, Young TK, Dewailly E, Ebbesson SO: Indigenous health in the Arctic: an overview of the circumpolar Inuit population. Scand J Public Health 2004, 32:390-395.

14. Kuhnlein HV, Receveur O, Soueida R, Egeland GM: Arctic indigenous peoples experience the nutrition transition with changing dietary patterns and obesity. J Nutr 2004, 134:1447-1453.

15. Batal M, Gray-Donald K, Kuhnlein HV, Receveur O: Estimation of traditional food intake in indigenous communities in Denendeh and the Yukon. Int J Circumpolar Health 2005, 64:46-54

16. Counil E, Dewailly E, Bjerregaard $P$, Julien P: Trans-polar-fat: all Inuit are not equal. Brit J Nutr 2008, 100:703-706

17. Hopping BN, Erber E, Mead E, Sheehy T, Sharma S: Socioeconomic indicators and frequency of traditional food, junk food, and fruit and vegetable consumption among Inuit adults in the Canadian Arctic. J Hum Nutr Diet 2010, 23(Suppl. 1):51-58.

18. Hopping BN, Mead E, Erber E, Sheehy T, Roache C, Sharma S: Dietary adequacy of Inuit in the Canadian Arctic. J Hum Nutr Diet 2010, 23(Suppl. 1):27-34

19. Mead E, Gittelsohn J, Roache C, Sharma S: Healthy food intentions and higher socioeconomic status are associated with healthier food choices in an Inuit population. J Hum Nutr Diet 2010, 23(Suppl. 1):83-91.

20. Sharma S, Cao X, Roache C, Buchan A, Reid R, Gittelsohn J: Assessing dietary intake in a population undergoing a rapid transition in diet and lifestyle: the Arctic Inuit in Nunavut, Canada. Brit J Nutr 2010, 103:749-759.

21. Government of Nunavut: Nunavut Communities. 2008. Avaiulable at: http://www.gov.nu.ca/files/Nunavut\%20Communities\%20Jan\%2008.pdf. Accessed on November 19th, 2011.

22. Nunavut Bureau of Statistics: Nunavut Quick Facts. 2008. Available at: http://www.eia.gov.nu.ca/stats/. Accessed on November 19th, 2011.

23. Statistics Canada: Age and sex structure: Canada, provinces and territories. 2011:2010. Available at: http://www.statcan.gc.ca/pub/91-209-x/2011001/ article/11511-eng.htm. Accessed on November 13th, 2011.

24. Anctil M: Survey Highlights, Nunavik Inuit Health Survey 2004, Qanuippitaa? How are we?. Quebec: Institut National de santé publique du Québec (INSPQ) \& Nunavik Regional Board of Health and Social Services (NRBHSS); 2008. Available at: http://www.inspq.qc.ca/pdf/publications/ 774_ESISurveyHighlights.pdf. Accessed on November 19th, 2011.

25. Circumpolar Inuit Cancer Review Working Group, Kelly J, Lanier A, Santos M, Healey S, Louchini R, Friborg J, Young K, Ng C: Cancer among the circumpolar Inuit, 1989-2003. II. Patterns and trends. Int J Circumpolar Health 2008, 67:408-420.

26. Public Health Agency of Canada: Chronic Disease Infobase, Malignant neoplasms, age-standardized mortality rates, all ages, both sexes. 2011:2007. Available at: http://204.187.39.30/surveillance/Maps.aspx. Accessed on November 19th, 2011.

27. Public Health Agency of Canada: Chronic Disease Infobase, Diseases of the circulatory system, age-standardized mortality rate, per 100,000, all ages, both sexes. 2011:2000-2004. Available at: http://204.187.39.30/surveillance/ Maps.aspx. Accessed on November 19th, 2011

28. Wilkins $R$, Uppal S, Finès $P$, Senecal $S$, Guimond $E$, Dion R: Life expectancy in the Inuit-inhabited areas of Canada, 1989 to 2003. Health Rep 2008, 19:7-19.

29. Gaziano JM: Fifth phase of the epidemiologic transition: the age of obesity and inactivity. JAMA 2010, 303:275-276.

30. de Castro JM: Genetic influences on daily intake and meal patterns of humans. Physiol Behav 1993, 54:633-639.

31. Young LR, Nestle M: Expanding portion sizes in the US marketplace: implications for nutrition counseling. J Am Diet Assoc 2003, 103:231-234.

32. Young LR, Nestle M: The contribution of expanding portion sizes to the US obesity epidemic. Am J Public Health 2002, 92:246-249.

33. Nestle M: Increasing portion sizes in American diets: More calories, more obesity. J Am Diet Assoc 2003, 103:39-40.

34. Kral TVE, Rolls BJ: Energy density and portion size: their independent and combined effects on energy intake. Physiol Behav 2004, 54:131-138.

35. Ello-Martin JA, Ledikwe JH, Rolls BJ: The influence of food portion size and energy density on energy intake: implications for weight management. Am J Clin Nutr 2005, 82(1 Suppl.):236S-241S.

36. Ledikwe JH, Ello-Martin JA, Rolls BJ: Portion sizes and the obesity epidemic. J Nutr 2005, 135:905-909.

37. Schwartz J, Byrd-Bredbenner C: Portion distortion: typical portion sizes selected by young adults. J Am Diet Assoc 2006, 106:1412-1418.

38. Steenhuis $\mid H$, Vermeer WM: Portion size: review and framework for interventions. Int J Behav Nutr Phys Act 2009, 6:58.

39. Duffey KJ, Popkin BM: Energy density, portion size, and eating occasions: contributions to increased energy intake in the United States, 1977-2006. PLoS Med 2011, 8(6):e1001050 [Epub 2011 Jun 28].

40. Levitsky DA, Pacanowski CR: Free will and the obesity epidemic. Public Health Nutr 2011, 19:1-16 [Epub ahead of print].

41. Nielsen SJ, Popkin BM: Patterns and trends in food portion sizes, 1977-1998. JAMA 2003, 289:450-453.

42. Steenhuis $\mathrm{H}$, Leeuwis $\mathrm{FH}$, Vermeer WM: Small, medium, large or supersize: trends in food portion sizes in The Netherlands. Public Health Nutr 2010, 13:852-857.

43. Piernas C, Popkin BM: Food portion patterns and trends among U.S. children and the relationship to total eating occasion size, 1977-2006. J Nutr 2011, 141:1159-1164 [Epub 2011 Apr 27].

44. Diliberti N, Bordi PL, Conklin MT, Roe LS, Rolls BJ: Increased portion size leads to increased energy intake in a restaurant meal. Obes Res 2004, 12:562-568.

45. Rolls BJ, Roe LS, Kral TV, Wall DE: Increasing the portion size of a packaged snack increases energy intake in men and women. Appetite 2004, 42:63-69.

46. Rolls BJ, Roe LS, Meengs JS, Wall DE: Increasing the portion size of a sandwich increases energy intake. J Am Diet Assoc 2004, 104:367-372.

47. Flood JE, Roe LS, Rolls BJ: The effect of increased beverage portion size on energy intake at a meal. J Am Diet Assoc 2006, 106:1984-1990.

48. Kelly MT, Wallace JM, Robson PJ, Rennie KL, Welch RW, Hannon-Fletcher MP, Brennan S, Fletcher A, Livingstone MB: Increased portion size leads to a sustained increase in energy intake over $4 \mathrm{~d}$ in normal-weight and overweight men and women. Br J Nutr 2009, 102:470-477.

49. Rolls BJ, Roe LS, Meengs JS: Larger portion sizes lead to a sustained increase in energy intake over 2 days. J Am Diet Assoc 2006, 106:543-549.

50. Rolls BJ, Roe LS, Meengs JS: The effect of large portion sizes on energy intake is sustained for 11 days. Obesity 2007, 15:1535-1543.

51. Rolls BJ, Roe LS, Meengs JS: Reductions in portion size and energy density of foods are additive and lead to sustained decreases in energy intake. Am J Clin Nutr 2006, 83:11-17.

52. Flood JE, Rolls BJ: Soup preloads in a variety of forms reduce meal energy intake. Appetite 2007, 49:626-634.

53. Rolls BJ: Plenary Lecture 1: Dietary strategies for the prevention and treatment of obesity. Proc Nutr Soc 2010, 69:70-79.

54. Pakseresht M, Sharma S: Validation of a quantitative food frequency questionnaire for Inuit population in Nunavut, Canada. J Hum Nutr Diet 2010, 23(Suppl. 1):67-74.

55. Sharma S, Gittelsohn J, Rosol R, Beck L: Addressing the public health burden caused by the nutrition transition through the Healthy Foods North nutrition and lifestyle intervention programme. J Hum Nutr Diet 2010, 23(Suppl. 1):120-127. 
56. Vermeer WM, Steenhuis $\mathrm{H}$, Seidell JC: Portion size: a qualitative study of consumers' attitudes toward point-of-purchase interventions aimed at portion size. Health Educ Res 2010, 25:109-120.

57. World Health Organisation: Obesity: preventing and managing the global epidemic: report of a WHO consultation. World Health Organ Tech Rep Ser 2000, 894:1-253.

58. Kuhnlein HV, Chan HM: Environment and contaminants in traditional food systems of northern indigenous peoples. Ann Rev Nutr 2000, 20:595-626.

59. Environment Canada: National Climate Data and Information Archive, Canadian Climate Normals; 2011:1971-2000. Available at: http://climate.weatheroffice.gc. ca/climate_normals/index_e.html. Accessed on June 5th, 2013.

60. Health Canada: Nutrient Value of Some Common Foods - Booklet. 2008. Available at: http://www.hc-sc.gc.ca/fn-an/nutrition/fiche-nutri-data/ nutrient_value-valeurs_nutritives-tc-tm-eng.php. Accessed on November 19th, 2011.

61. Nielsen SJ, Popkin BM: Changes in beverage intake between 1977 and 2001. Am J Prev Med 2004, 2:205-210.

62. Wolf A, Bray GA, Popkin BM: A short history of beverages and how our body treats them. Obes Rev 2008, 9:151-164.

63. Malik VS, Popkin BM, Bray GA, Després JP, Hu FB: Sugar-sweetened beverages, obesity, type 2 diabetes mellitus, and cardiovascular disease risk. Circulation 2010, 121:1356-1364.

64. Johnson RK, Appel $\amalg$, Brands M, Howard BV, Lefevre M, Lustig RH, Sacks F, Steffen LM, Wylie-Rosett J: Dietary sugars intake and cardiovascular health. A scientific statement from the American Heart Association. Circulation 2009, 120:1011-1020.

65. Mattes RD: Fluid energy-Where's the problem? J Am Diet Assoc 2006 106:1956-1961.

66. Bray GA: The epidemic of obesity and changes in food intake: the Flouride Hypothesis. Physiol Behav 2004, 82:115-121.

67. Anon: An epidemic of risk factors for cardiovascular disease. Lancet 2011, 377(9765):527.

68. Lloyd-Jones DM, Hong Y, Labarthe D, Mozaffarian D, Appel L, Van Horn L, Greenlund K, Daniels S, Nichol G, Tomaselli GF, Arnett DK, Fonarow GC, Ho PM, Lauer MS, Masoudi FA, Robertson RM, Roger V, Schwamm LH, Sorlie P, Yancy CW, Rosamond WD: Defining and setting national goals for cardiovascular health promotion and disease reduction: the American Heart Association's strategic Impact Goal through 2020 and beyond. Circulation 2010, 121:586-613.

69. Lloyd-Jones DM, Leip EP, Larson MG, D'Agostino RB, Beiser A, Wilson PW, Wolf PA, Levy D: Prediction of lifetime risk for cardiovascular disease by risk factor burden at 50 years of age. Circulation 2006, 113:791-798.

70. Capewell S, Ford ES, Croft JB, Critchley JA, Greenlund KJ, Labarthe DR: Cardiovascular risk factor trends and potential for reducing coronary heart disease mortality in the United States of America. Bull World Health Organ 2010, 88:120-130.

71. Capewell S, Lloyd-Jones DM: Optimal cardiovascular prevention strategies for the 21st century. JAMA 2010, 304:2057-2058.

doi:10.1186/1475-2891-12-70

Cite this article as: Sheehy et al.: Eating habits of a population undergoing a rapid dietary transition: portion sizes of traditional and non-traditional foods and beverages consumed by Inuit adults in Nunavut, Canada. Nutrition Journal 2013 12:70.

\section{Submit your next manuscript to BioMed Central and take full advantage of:}

- Convenient online submission

- Thorough peer review

- No space constraints or color figure charges

- Immediate publication on acceptance

- Inclusion in PubMed, CAS, Scopus and Google Scholar

- Research which is freely available for redistribution

Submit your manuscript at www.biomedcentral.com/submit
C Biomed Central 